\title{
Construction and Calibration of the NIST Large-Area-Source X-Ray Counting System
}

J. M. R. Hutchinson, M. P. Unterweger, and P. A. Hodge

National Institute of Standards and Technology, Gaithersburg, MD 20899
This paper describes the construction and calibration of the NIST large area $\mathrm{x}$-ray counting system. ${ }^{238} \mathrm{Pu}$ sources 8 in $(20.32 \mathrm{~cm})$ by 5 in $(12.70 \mathrm{~cm})$ thick, emitting $L x$ rays in the range of $12-20$ $\mathrm{keV}$ are calibrated for total emission rate and also for rate through a centrally located 3 in $(7.63 \mathrm{~cm})$ diameter aperture. Alpha particle emission rates are obtained using the known x-ray to alpha particle abundances. The sources will be used to calibrate alpha-particle surface monitors.

Key words: calibration; efficiency curve; large area source; plutonium-238; proportional counting; $x$ ray.

Accepted: October 30, 1991

\section{Introduction}

Recently the National Institute of Standards and Technology (NIST) has developed a calibrated system for measuring the $L$ x-ray-counting rate of large area sources of plutonium. The system was requested by the United States Air Force (USAF) primary calibration laboratory in order to calibrate large area standards for its secondary and tertiary laboratories. The objective was to tie the USAF calibrations to NIST standards and thereby take the first step towards "traceability" of USAF surface monitoring equipment.

The program required the construction of a jig which holds a $\mathrm{NaI}(\mathrm{Tl})$ detector at a precise distance from a vertically moveable platform on which the large area source may be positioned. Distances from the source-to-detector can be adjusted and held accurately. The second part of the program was to determine the ${ }^{238} \mathrm{Pu} L$ x-ray counting efficiencies as a function of source-to-detector distance for both a rectangular source and circular sources of various diameters. A number of published calculations and tables exist of photon effi- ciencies at various distances from $\mathrm{NaI}(\mathrm{Tl})$ detectors for these geometries [1]. Generally, though, the accuracies given in these reports are in the range of 5-10 percent for the dimensions of the present arrangement, especially for close-in geometries for which the source dimensions exceed those of the detector by a wide margin. The aim of the program is to provide efficiency values with accuracies of 5 percent or less.

The calibration procedure was first to check the system calibration with a calibrated point source which can give the efficiencies for all distances from an analytical expression of the solid angle subtended by the "black" detector from the source. Values of the count rates for rectangular and circular large area sources at various distances were fitted to a mathematical expression which reduced to the point source values for zero source size. The calibration of one of the sources was then compared with the $x$-ray results by alpha-particle counting. 
The utility of photon measurements for field monitoring is described by the NARP manual [2] which recommends low-energy gamma instruments for field surveys of plutonium contamination. Alpha measurements should be used "primarily for personnel monitoring and when field use is necessary, on smooth surfaces only, e.g., pavement and building surfaces."

\section{Large Area X-Ray Counting System}

The large-area-defined-solid angle $\mathrm{NaI}(\mathrm{Tl}) \mathrm{x}$-ray counting system is shown schematically in Fig. 1 and in a photograph in Fig. 2. It consists of a $1 / 32$ in $(0.079 \mathrm{~cm})^{1}$ thick, $31 / 32$ in $(2.46 \mathrm{~cm})$ diameter $\mathrm{NaI}(\mathrm{Tl})$ detector. The detector is thick enough to ensure that all impinging $U L \mathrm{x}$ rays (following the alpha decay of ${ }^{238} \mathrm{Pu}$ ) are absorbed except those which are lost in the 0.005 in $(0.013 \mathrm{~cm}) \mathrm{Be}$ window and the $\mathrm{Al}$ reflector. The detector is mounted on an XP1010 phototube which has a noise level equivalent to one $\mathrm{keV}$ photon energy. The platform is vertically moveable over approximately 14 in $(35.56 \mathrm{~cm})$ by means of a precision spindle which

GEOMETRICAL PARAMETERS OF THE LARGE AREA X-RAY SOURCE CALIBRATOR

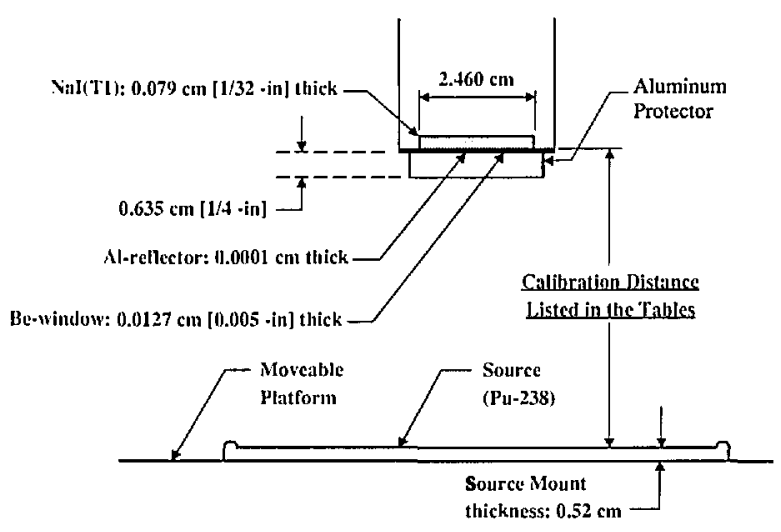

OTHFR PARMMFTERS NFEDED TO USE THE IISTED TABLLES $\mathrm{X}$-ray Probability: 0.1155

Rectangular Source Dimensions: $12.75 \mathrm{~cm} \times 20.25 \mathrm{~cm}$

Circular Baffic Dinneter: $7.59 \mathrm{~cm}$ [3 -in]

Fig. 1. Schematic diagram of the $x$-ray system.

\footnotetext{
${ }^{1}$ The dimensions are given in U.S. customary units with their SI equivalents in parentheses because the instrument is designed and calibrated in inches and fractions thereof.
}

is moved manually with a wheel which can reproduce the vertical position to 0.001 in $(0.003 \mathrm{~cm})$. The source platform is large enough to be able to mount any size source that could be useful for the calibration of surface monitoring systems. Tests were made on the NIST coordinate measuring machine. The true distance of the platform for selected positions is given in Table 1 .

Table 1. Coordinate measurement data showing setting accuracies of the platform movement with the spindle

\begin{tabular}{|c|c|c|}
\hline $\begin{array}{l}\text { Dia } \\
\text { (in) }\end{array}$ & Dial wheel setting & $\begin{array}{c}\text { Distance measurement from } \\
0.000 \text { setting }\end{array}$ \\
\hline .000 & $(0.0)$ & 0.000 \\
\hline 1.000 & $(2.54)$ & 0.9990 \\
\hline 2.000 & $(5.08)$ & 2.0000 \\
\hline 3.000 & (7.62) & 2.9990 \\
\hline 4.000 & (10.16) & 4.0000 \\
\hline 5.000 & (12.70) & 4.9995 \\
\hline 6.000 & (15.24) & 6.0010 \\
\hline 7.000 & (17.78) & 6.9995 \\
\hline 8.000 & (20.32) & 8.0005 \\
\hline 9.000 & $(22.86)$ & 9.0010 \\
\hline 10.000 & (25.40) & 10.0010 \\
\hline 11.000 & (27.94) & 11.0020 \\
\hline 12.000 & $(30.48)$ & 12.0020 \\
\hline 13.000 & $(33.02)$ & 13.0010 \\
\hline 14.000 & $(35.56)$ & 14.0000 \\
\hline
\end{tabular}

The vertical variability from horizontal is approximately 0.014 in $(0.036 \mathrm{~cm})$ maximum over the face of the platform. Deviation of the center from the labeled value is 0.002 in $(0.006 \mathrm{~cm})$.

A schematic diagram of the electronics is shown in Fig. 3. The pulses are fed from the amplifier with microsecond resolving time into the pulse height analyzer whose output is recorded on a PC. A typical $\mathrm{NaI}(\mathrm{Tl})$ spectrum of the $\mathrm{U} L \mathrm{x}$ rays in the decay of ${ }^{238} \mathrm{Pu}$ is shown in Fig. 4.

\section{Sources and Baffles}

A NIST "point" source was used to check for the correct functioning of the system and to determine the efficiency of the detector for $x$ rays at large distances. It consists of ${ }^{238} \mathrm{Pu}$ electroplated onto a thin platinum foil $6 \mathrm{~mm}$ in diameter and mounted onto a 1 in $(2.54 \mathrm{~cm})$ diameter polished stainless steel disc. The photon emission spectrum with a $\mathrm{Ge}$ detector from this source is shown in Fig. 5. The U $L \mathrm{x}$-ray peaks occur between 11 and $20 \mathrm{keV}$. Contributions from activation of the platinum occur at 8 and $11 \mathrm{keV}$ and are $7 \pm 2$ percent of the intensity 


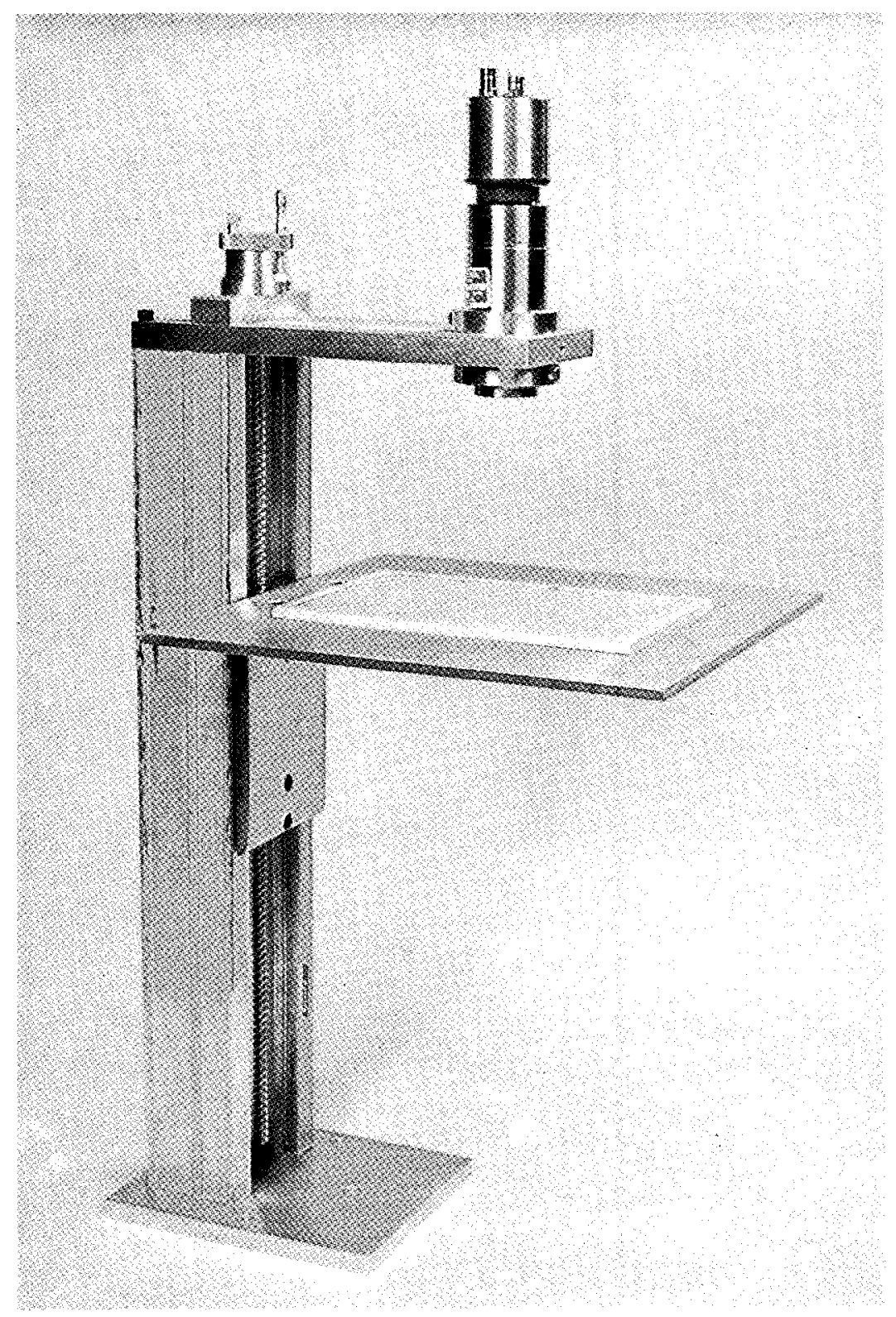

Fig. 2. Photograph of the $x$-ray system.

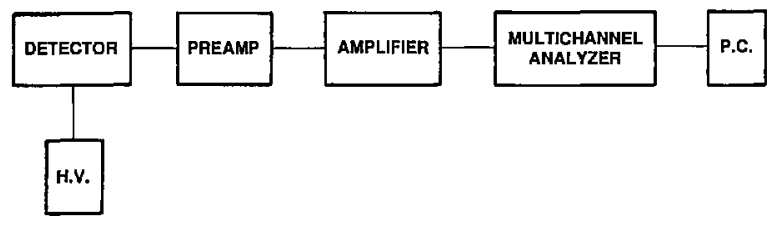

Fig. 3. Schematic diagram of the electronics of the x-ray system.

of the $U L \mathrm{x}$ rays. In addition, the possibility exists for self activation of the source, i.e., high energy $L$ $x$ rays stimulating lower energy $x$ rays in the plutonium or being lost entirely from the photon spec- trum. Because the solid angle from source to detector can be calculated exactly (within the accuracies of the measured dimensions of the sourceto-detector distance and diameter of the detector) and the source activity is known, the correct functioning of the system was checked with measurements with this source.

A large area source is shown in Fig. 6. The photon emission spectrum with a $\mathrm{Ge}$ detector from this source is shown in Fig. 7. The dimensions are 8 in $(20.32 \mathrm{~cm})$ by 5 in $(12.70 \mathrm{~cm})$. Disc sources were produced by covering it and other similar sources with baffles of 1 in $(2.54 \mathrm{~cm}), 2$ in $(5.08 \mathrm{~cm})$, and 


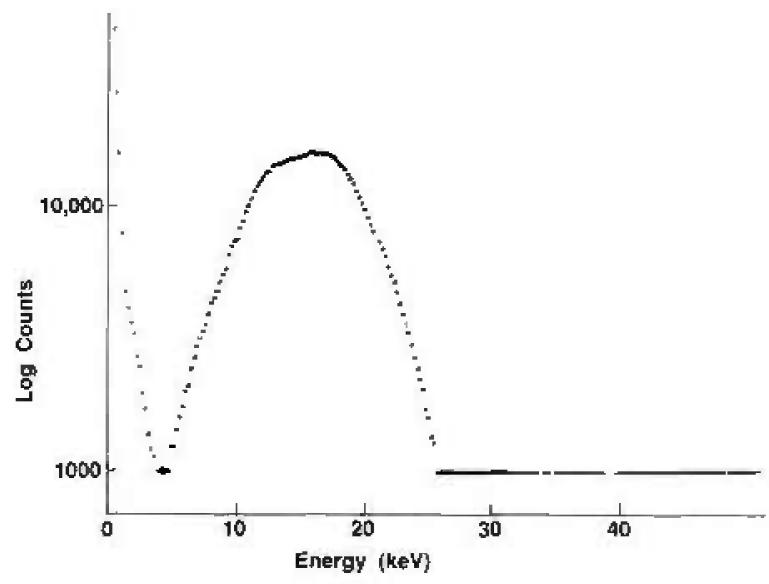

Fig. 4. Spectrum of a NaI(TI) source.

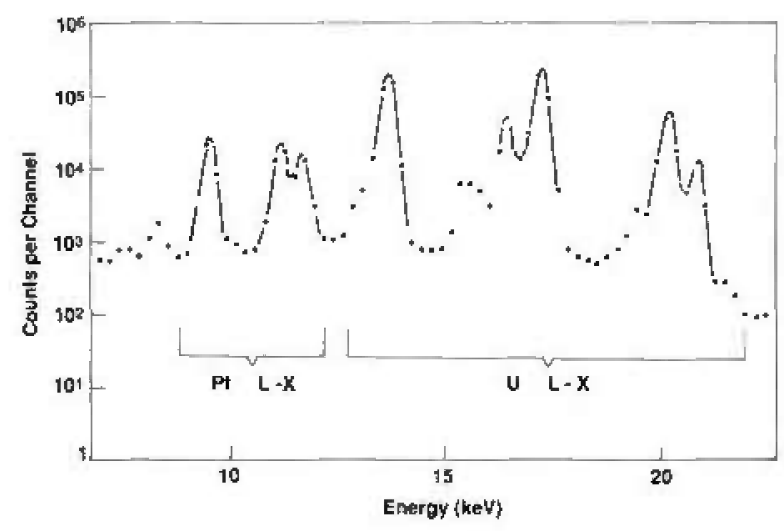

Fig. 5. Ge spectrum of a ${ }^{241} \mathrm{Am}$ point source electroplated on a platinum substrate.
3 in $(7.62 \mathrm{~cm})$ diameter holes cut in either stainless steel or aluminum (6061) plates. The plutonium is anodized onto the aluminum foil which is attached to a solid aluminum baseplate. A radiogram is shown of one of the "hotter" sources showing an array of radioactive sites, $4 \mathrm{~mm}$ distance center-tocenter (Fig. 8). The weaker sources were also anodized but, in these, the radioactivity is continuously distributed. The observed homogeneity of these sources has been discussed elsewhere [3] and was found to be in the range of \pm 5 percent for a 3 in $(7.62 \mathrm{~cm})$ diameter area.

\section{X-Ray Efficiency Curve \\ 4.1 Point Source}

Measurements were taken of the point source with the $\mathrm{NaI}(\mathrm{Tl})$ detector at distances from 1 in $(2.54 \mathrm{~cm})$ to 7 in $(17.78 \mathrm{~cm})$ from the source to the face of the detector.

The expression for the solid angle from a point source at a distance $h$ to a circular aperture with radius, $r$, is:

$$
\epsilon=0.5-h / 2 R
$$

where $\epsilon$ is the solid angle, or in this case, the efficiency, and $R^{2}=r^{2}+h^{2}$. A correction was made for the scattering by the intervening air, and absorption by the Be window and the $\mathrm{Al}$ reflector.

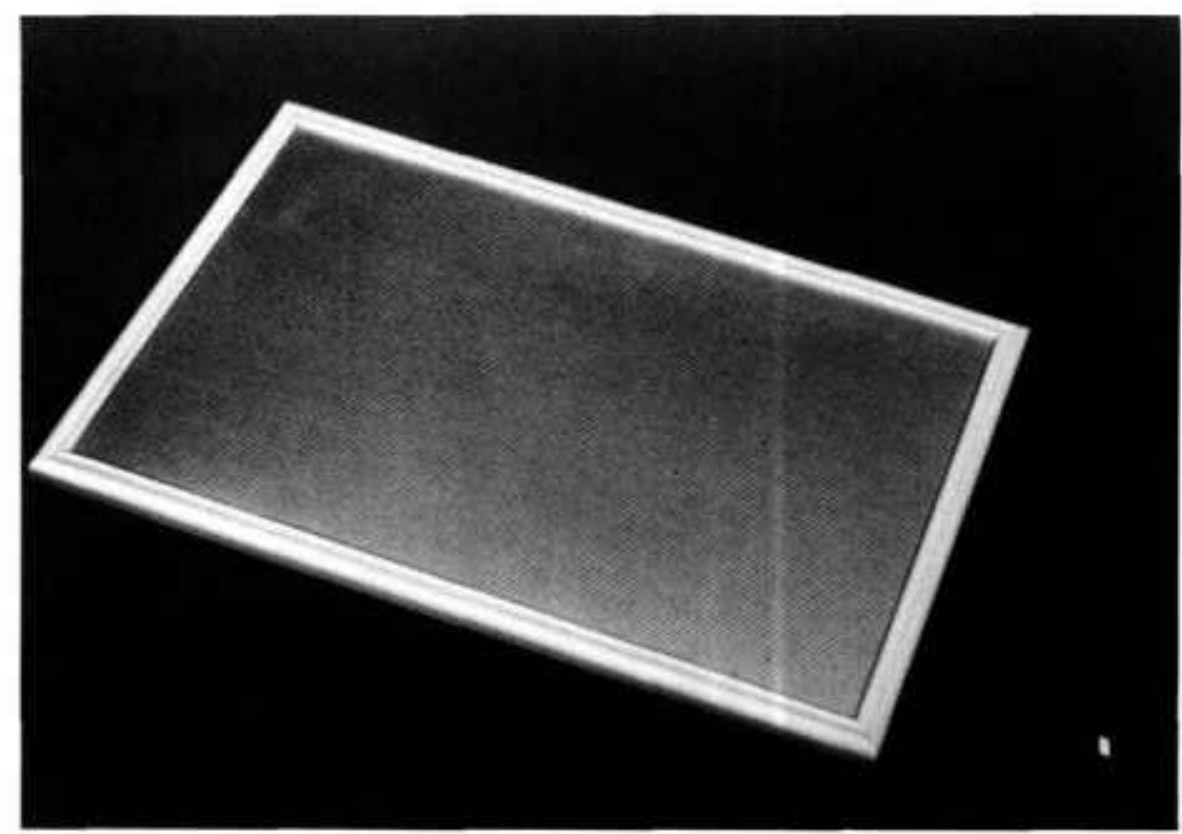

Ftg. 6. Large area ${ }^{239} \mathrm{Pu}$ source. 


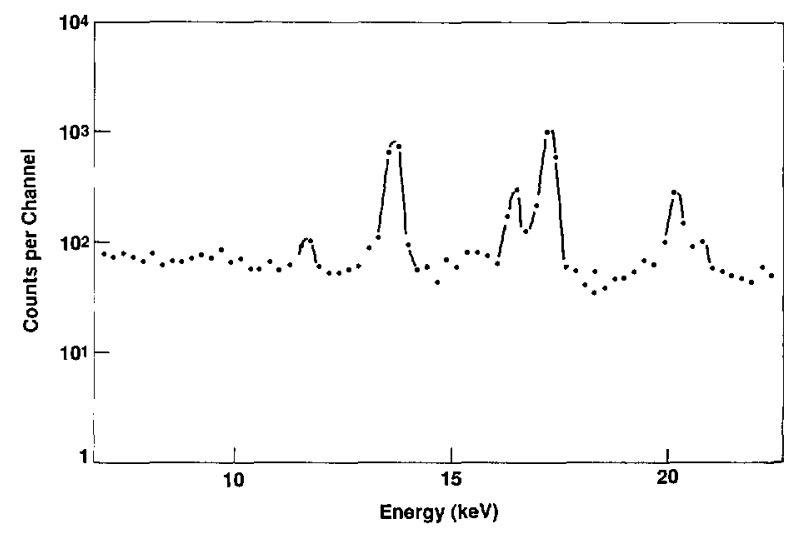

Fig. 7. Ge spectrum of the large area ${ }^{238} \mathrm{Pu}$ source.

The experimental value appears to be 5 percent greater than the calculated value. However $7 \pm 2$ percent of the $\mathrm{NaI}(\mathrm{Tl})$ peak has been determined to be stimulated $x$ rays from the platinum substrate. Subtracting this value leaves the experimental value in good agreement with the prediction in Eq. (1).

\subsection{Large Area Sources}

The value for the activity of source AA372, the most active of the sources, was determined two ways: (i) By taking the count rate at 14 in $(35.56 \mathrm{~cm})$ with a 3 in $(7.62 \mathrm{~cm})$ disc baffle and assuming that it was essentially a point source at that distance and computing the efficiency according to Eq. (1) (adjusting for air and $\mathrm{Be}$ and $\mathrm{Al}$ reflector absorption). The result was multiplied by the ratio of the total rectangular area to the area of the 3 in disc to obtain the total activity, and

(ii) By alpha-particle counting AA370 [3], a relatively low activity source that would not overload the internal gas counting system, and comparing AA370 and AA372 by x-ray counting and external alpha counting, and from these data determining the activity of AA372. A source self-absorption correction of 5.8 percent was determined as follows. (It should be remembered that the source is anodized so that the active material is embedded in aluminum oxide and significant absorption is to be expected.)

A Si surface barrier spectrum as shown in Fig. 9 was taken. The distribution, except for a small amount of tailing, starts at 80 percent of the range. This is because the activity at its deepest is impregnated to a depth corresponding to 20 percent of the

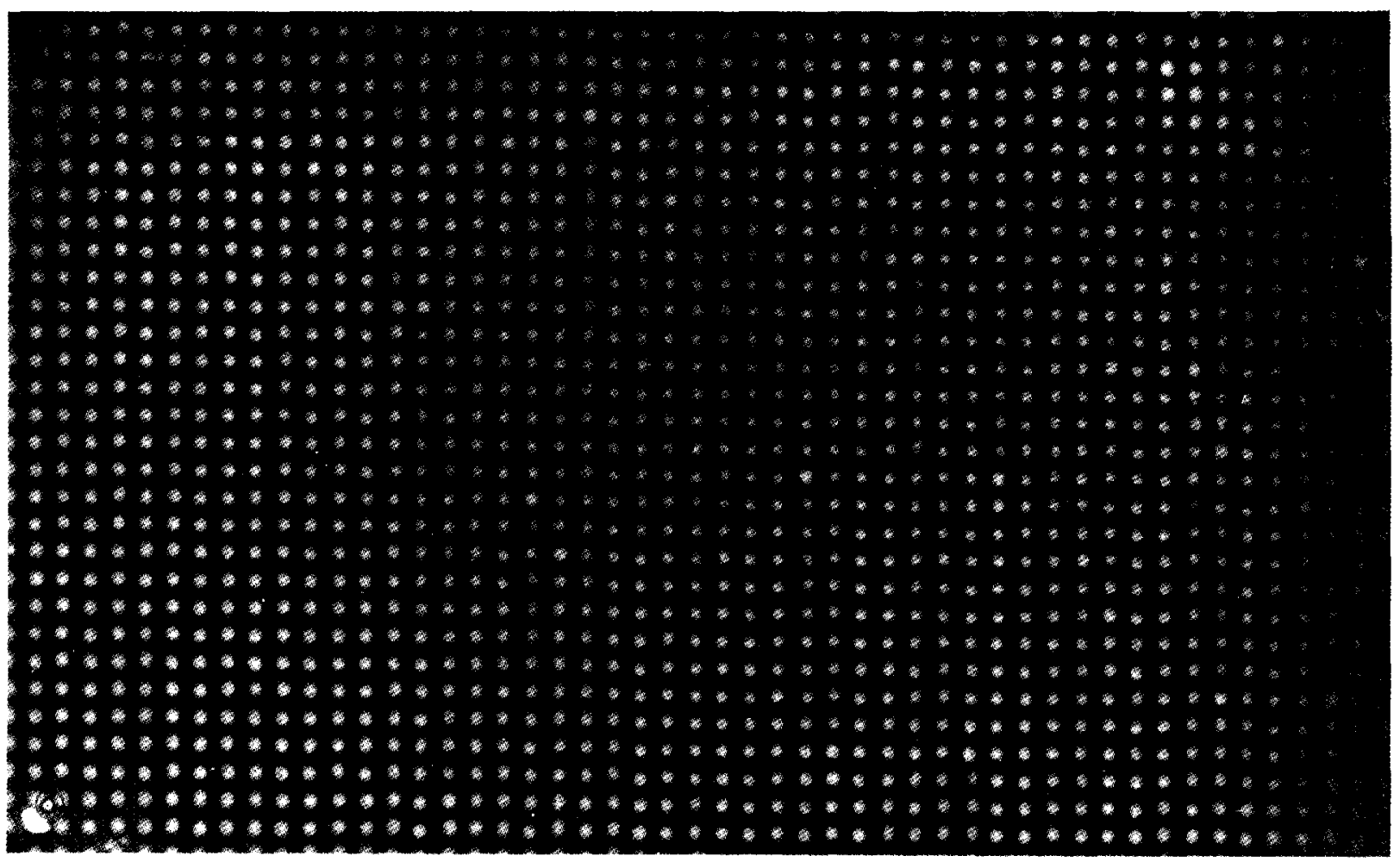

Fig. 8. Radiograph of the large area source showing an array of radioactive sites. 
range. The $C_{2 \pi} / N_{0}$ value for this situation has been calculated by Lucas et al. [4]. However, the spectrum peaks at 100 percent of the range and tails off at lower energies corresponding to a depth profile for the activity of maximum near the surface and tailing off to a maximum depth of 20 percent of the range.

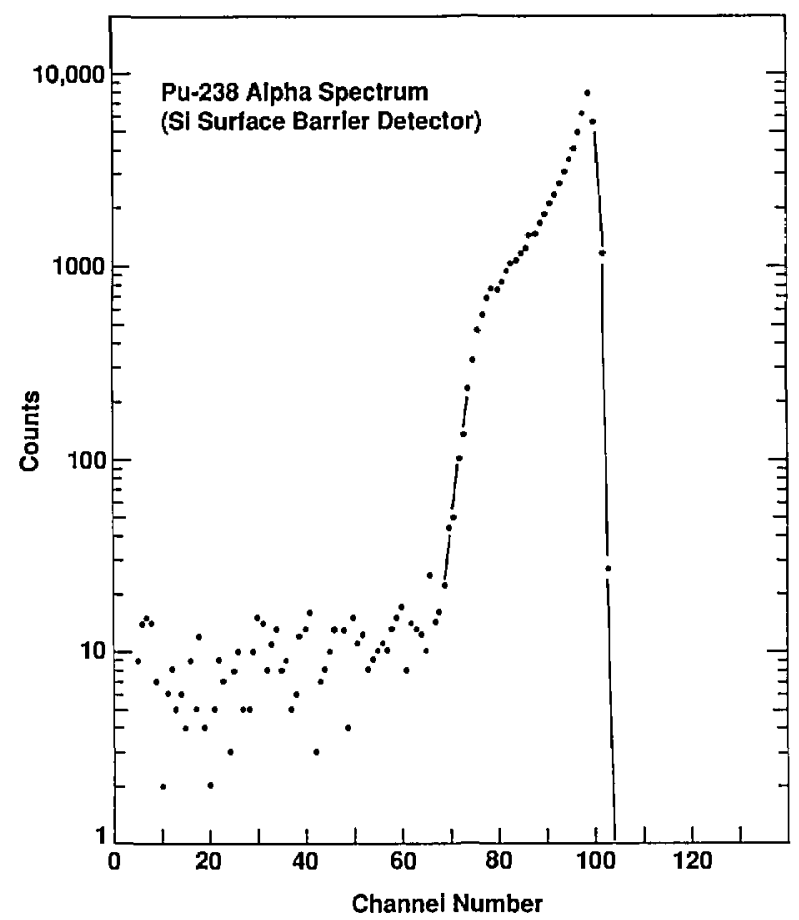

Fig. 9. Si surface barrier spectrum of a large area ${ }^{238} \mathrm{Pu}$ source.

To determine the overall $C_{2 \pi} / N_{0}$ value, values of $C_{2 \pi} / N_{0}$ at $80,85,90,95$, and 100 percent of the range were calculated. Counts in a rectangular area corresponding to $80-100$ percent of the range were calculated from the pulse height spectrum and assigned a corresponding $C_{2 \pi} / N_{0}$ value. This fraction of the spectrum was subtracted, and the 85 percent fraction was then calculated, etc. The overall $C_{2 \pi} /$ $N_{0}$ was taken as the weighted average. The weighted sets of $C_{2 \pi} / N_{0}$ were added together with the result that the average value of $C_{2 \pi} / N_{0}$ for the large area source was 0.473 , or a correction to the activity of 5.8 percent which agreed with the manufacturer's value of 5.5 percent. The overall results are shown below.

Activity of AA372 ${ }^{238} \mathrm{Pu}$ Source by Two Methods

\section{X-Ray Counting}

$$
\begin{aligned}
D P S & =N f(1 / \epsilon)(R / 0.1155) \\
& =\left(4.3141\left(1 / 0.299 \times 10^{-3}\right)(5.70 / 0.1155)\right. \\
& =7.12 \times 10^{5}(5 / 4 / 91)
\end{aligned}
$$

where $\quad N=$ cps at 14 in $(35.56 \mathrm{~cm})$

$f=\mathrm{x}$-ray absorption in air, $\mathrm{Be}, \mathrm{Al}$

$\epsilon=$ geometrical point source efficiency at 14 in $(35.56 \mathrm{~cm})(L \mathrm{x} / \mathrm{dps})=0.1155$

Alpha Particle Counting

$$
\begin{aligned}
D P S & =C \times 2 \times S \times(372 / 370) \times D \\
& =2459 \times 2 \times 1.058 \times 148 \times 0.963 \\
& =7.41 \times 10^{5}
\end{aligned}
$$

where $\quad C=2 \pi \alpha$ count rate of $370(7 / 31 / 86) 2$ to convert to $4 \pi$

$S=$ scattering correction

$(372 / 370)=$ measured ratio by $x$-ray counting

$D=$ decay to $5 / 4 / 91$

The alpha results differ from the $x$-ray results by 4 percent, a value not outside the range of possible uncertainties as discussed in the next section.

$U \mathrm{X}$-ray' efficiency curves were then generated for the rectangular and disc shaped sources by first taking data at 1 in $(2.54 \mathrm{~cm})$ through 14 in $(35.56$ $\mathrm{cm}$ ) for these geometries. The data corrected for air, $\mathrm{Be}$, and $\mathrm{Al}$ absorption were fitted using a $\chi^{2}$ minimization technique which generated the following equations for the efficiency for the 3 in $(7.62 \mathrm{~cm})$ disc and the rectangular sources.

Circular source:

$$
\begin{aligned}
\epsilon_{\mathrm{cir}}=\epsilon_{\mathrm{pt}} & +\left(0.5-\epsilon_{\mathrm{pt}}\right)(-0.23095) \cdot\left(\frac{R}{r}\right)^{2} \cdot \frac{r^{4}}{\left(h^{2}+r^{2}\right)^{2}} \\
& +\left(0.5-\epsilon_{\mathrm{pt}}\right)(0.04236) \cdot\left(\frac{R}{r}\right)^{4} \cdot \frac{h^{2} \cdot r^{6}}{\left(h^{2}+r^{2}\right)^{4}}
\end{aligned}
$$

where $R=$ radius of source in $\mathrm{cm}(3.795 \mathrm{~cm})$.

Rectangular source:

$$
\begin{gathered}
\epsilon_{\mathrm{rec}}=\epsilon_{\mathrm{pt}}+\left(0.5-\epsilon_{\mathrm{pt}}\right)(-0.17197) \cdot \frac{\left(a^{2}+b^{2}\right)}{(2 r)^{2}} \cdot \frac{r^{4}}{\left(h^{2}+r^{2}\right)^{2}} \\
+\left(0.5-\epsilon_{\mathrm{pt}}\right)(0.03370) \cdot \frac{\left(a^{4}+(10 / 9) \cdot\left(a^{2} \cdot b^{2}\right)+b^{4}\right)}{(2 r)^{4}} \\
\cdot \frac{h^{2} \cdot r^{6}}{\left(h^{2}+r^{2}\right)^{4}}
\end{gathered}
$$

where $a$ and $b$ are the length and width of the rectangular source in $\mathrm{cm}(a=20.3 \mathrm{~cm}, b=12.725$ $\mathrm{cm})$ and where

$$
\epsilon_{\mathrm{pt}}=\frac{(0.5-h)}{\left(2 \cdot\left(h^{2}+r^{2}\right)^{1 / 2} \cdot 1.07\right.}
$$


where $h=$ distance from detector to source in $\mathrm{cm}$ $r=$ radius of detector in $\mathrm{cm}$ (1.230312).

The total efficiency curves,

$$
\left(\epsilon_{\text {cir }}\right)_{\text {total }}=\epsilon_{\text {cir }} f
$$

and

$$
\left(\epsilon_{\text {rec }}\right)_{\text {total }}=\epsilon_{\text {rec }} f
$$

where $f=\mathbf{x}$-ray absorption in air, $\mathrm{Be}$, and $\mathrm{Al}$ are shown in Figs. 10a and 10b and the total efficiency values for the measured distances are listed numerically in Tables 2 and 3.

\section{Uncertainty Listing}

The uncertainties in the value for the efficiencies in curves are as follows:

Activity of point source

Percent

Estimate of percentage of $\mathrm{Pt} x$ rays

1.0

$\mathrm{X}$-ray abundance

2.0

Air, $\mathrm{Be}, \mathrm{Al}$ absorption estimates

1.5

Uncertainties in fitted parameters

1.5

Counting uncertainties

1.5

Source positioning

0.2

Total $1 \mathrm{sd}$ (uncertainties taken in quadrature) 3.4

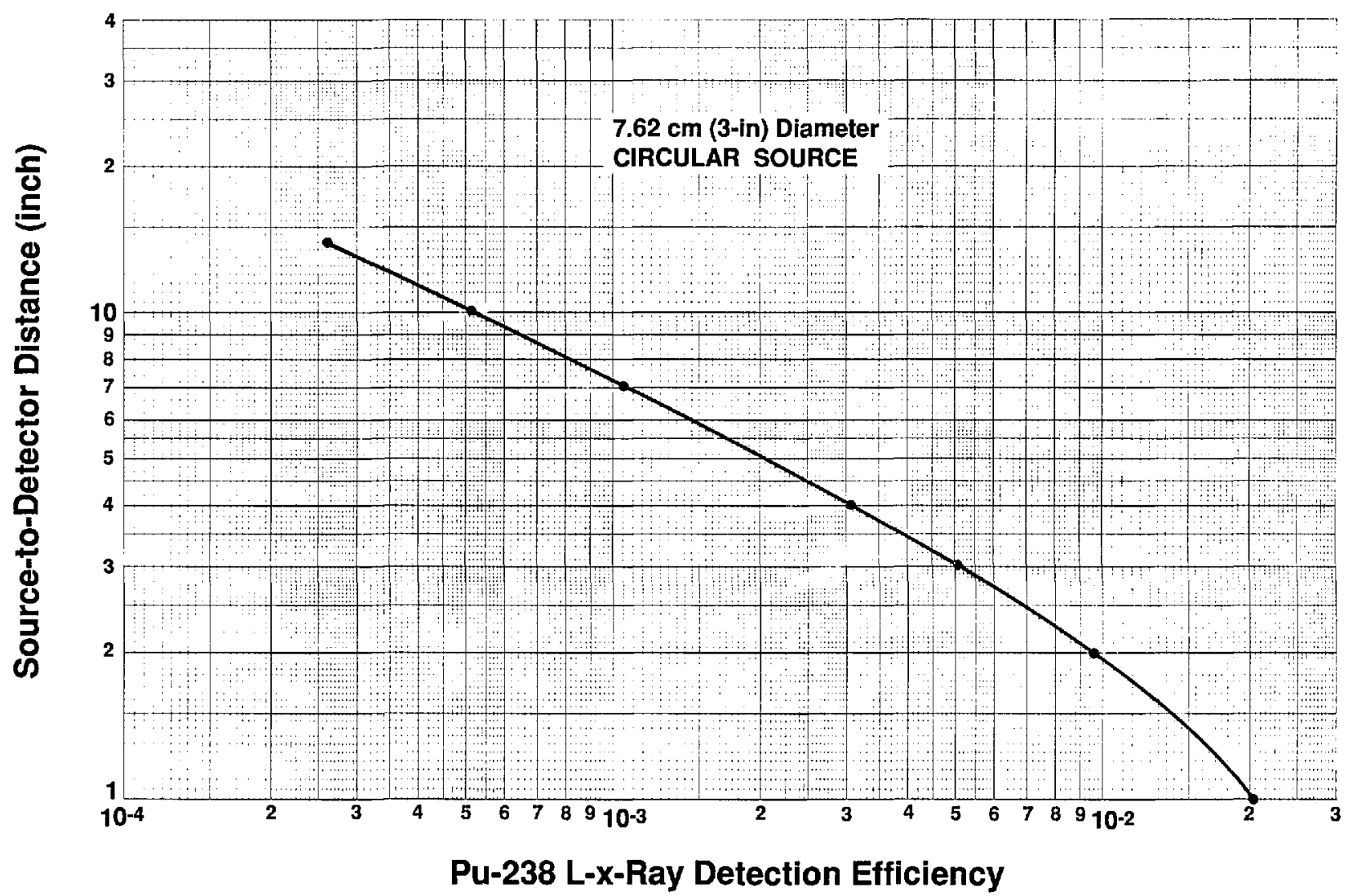

Fig. 10a. X-ray efficiency curve for the $3 \mathrm{in}(7.62 \mathrm{~cm})$ disc source as a function of distance from the front face of the NaI(Tl) detector. 


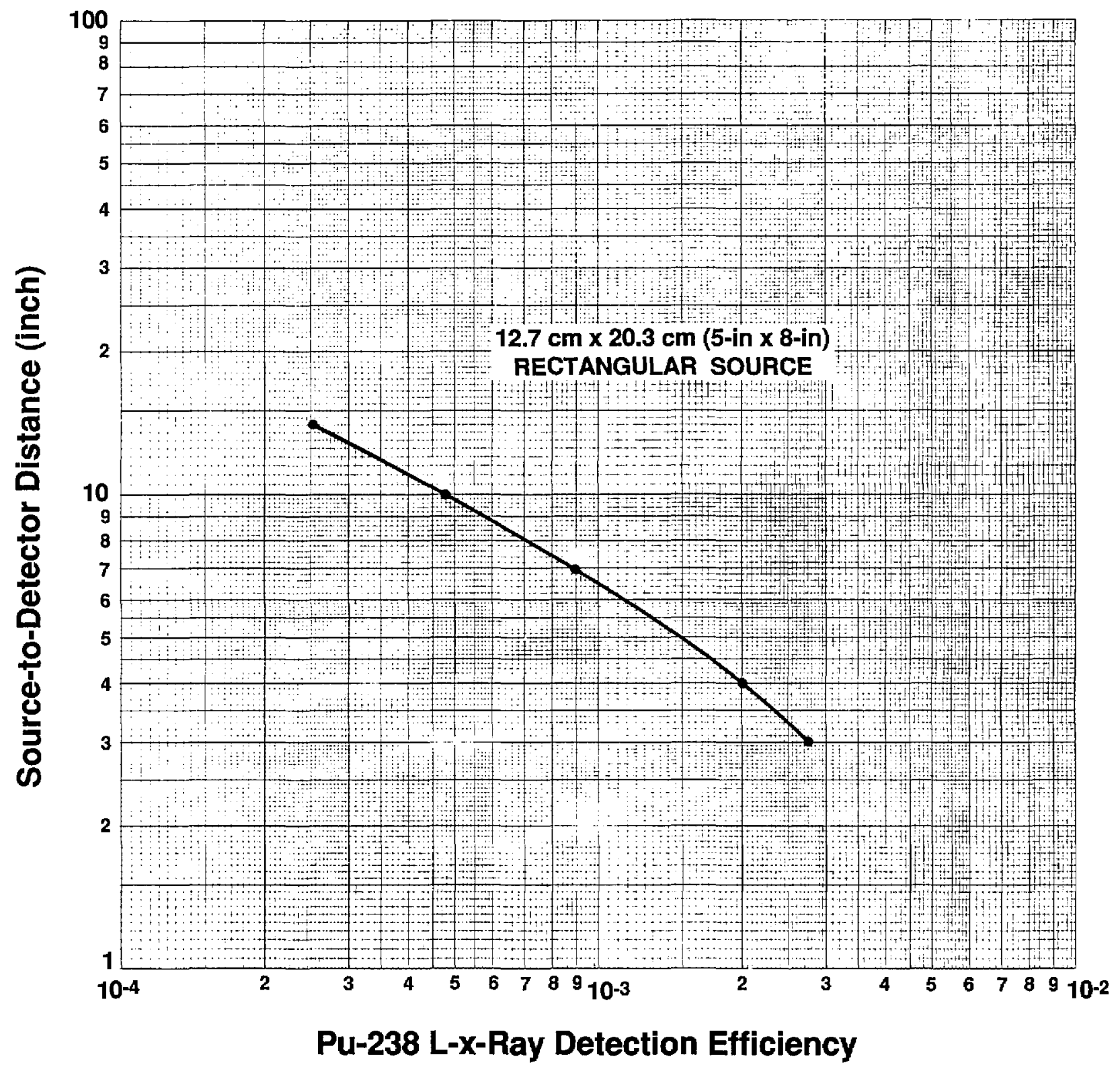

Fig 10b. X-ray efficiency curve for the 8 in $(20.32 \mathrm{~cm}) \times 5$ in $(12.70 \mathrm{~cm})$ rectangular source as a function of distance from the front face of the $\mathrm{NaI}(\mathrm{Tl})$ detector. 
Table 2. Numerical listing of the calculated and measured efficiencies for the 3 in diameter baffled source

\begin{tabular}{|c|c|c|c|}
\hline \multicolumn{2}{|c|}{$\begin{array}{l}\text { Source to detector } \\
\text { distance in in }\end{array}$} & \multirow{2}{*}{$\begin{array}{c}\begin{array}{c}\text { Calculated } \\
\text { efficiency }\end{array} \\
2.359 \times 10^{-2}\end{array}$} & \multirow{2}{*}{$\begin{array}{c}\begin{array}{c}\text { Measured } \\
\text { efficiency }\end{array} \\
2.360 \times 10^{-2}\end{array}$} \\
\hline 1.00 & $2.54 \mathrm{~cm}$ ) & & \\
\hline 1.25 & $3.18 \mathrm{~cm}$ ) & $1.951 \times 10^{-2}$ & \\
\hline 1.50 & $3.81 \mathrm{~cm})$ & $1.602 \times 10^{-2}$ & \\
\hline 1.75 & $4.45 \mathrm{~cm})$ & $1.317 \times 10^{-2}$ & \\
\hline 2.00 & $5.08 \mathrm{~cm}$ ) & $1.089 \times 10^{-2}$ & $1.081 \times 10^{-2}$ \\
\hline 2.25 & $5.72 \mathrm{~cm})$ & $9.086 \times 10^{-3}$ & \\
\hline 2.50 & $6.35 \mathrm{~cm})$ & $7.660 \times 10^{-3}$ & \\
\hline 2.75 & $6.99 \mathrm{~cm})$ & $6.522 \times 10^{-3}$ & \\
\hline 3.00 & $7.62 \mathrm{~cm})$ & $5.607 \times 10^{-3}$ & $5.634 \times 10^{-3}$ \\
\hline 3.25 & $8.26 \mathrm{~cm})$ & $4.863 \times 10^{-3}$ & \\
\hline 3.50 & $8.89 \mathrm{~cm})$ & $4.252 \times 10^{-3}$ & \\
\hline 3.75 & $(9.53 \mathrm{~cm})$ & $3.746 \times 10^{-3}$ & \\
\hline 4.00 & $(10.16 \mathrm{~cm})$ & $3.322 \times 10^{-3}$ & $3.360 \times 10^{-3}$ \\
\hline 4.25 & $(10.80 \mathrm{~cm})$ & $2.965 \times 10^{-3}$ & \\
\hline 4.50 & $(11.43 \mathrm{~cm})$ & $2.661 \times 10^{-3}$ & \\
\hline 4.75 & $(12.07 \mathrm{~cm})$ & $2.400 \times 10^{-3}$ & \\
\hline 5.00 & $(12.70 \mathrm{~cm})$ & $2.175 \times 10^{-3}$ & \\
\hline 5.25 & $(13.34 \mathrm{~cm})$ & $1.979 \times 10^{-3}$ & \\
\hline 5.50 & $(13.97 \mathrm{~cm})$ & $1.809 \times 10^{-3}$ & \\
\hline 5.75 & $(14.61 \mathrm{~cm})$ & $1.659 \times 10^{-3}$ & \\
\hline 6.00 & $(15.24 \mathrm{~cm})$ & $1.526 \times 10^{-3}$ & \\
\hline 6.25 & $(15.88 \mathrm{~cm})$ & $1.409 \times 10^{-3}$ & \\
\hline 6.50 & ( $16.51 \mathrm{~cm})$ & $1.304 \times 10^{-3}$ & \\
\hline 6.75 & $(17.15 \mathrm{~cm})$ & $1.211 \times 10^{-3}$ & \\
\hline 7.00 & $(17.78 \mathrm{~cm})$ & $1.127 \times 10^{-3}$ & $1.141 \times 10^{-3}$ \\
\hline 7.25 & $(18.42 \mathrm{~cm})$ & $1.051 \times 10^{-3}$ & \\
\hline 7.50 & $(19.05 \mathrm{~cm})$ & $9.829 \times 10^{-4}$ & \\
\hline 7.75 & $(19.69 \mathrm{~cm})$ & $9.208 \times 10^{-4}$ & \\
\hline 8.00 & $(20.32 \mathrm{~cm})$ & $8.644 \times 10^{-4}$ & \\
\hline 8.25 & $(20.96 \mathrm{~cm})$ & $8.129 \times 10^{-4}$ & \\
\hline 8.50 & $(21.59 \mathrm{~cm})$ & $7.658 \times 10^{-4}$ & \\
\hline 8.75 & ( $22.23 \mathrm{~cm})$ & $7.227 \times 10^{-4}$ & \\
\hline 9.00 & $(22.86 \mathrm{~cm})$ & $6.830 \times 10^{-4}$ & \\
\hline 9.25 & $(23.50 \mathrm{~cm})$ & $6.465 \times 10^{-4}$ & \\
\hline 9.50 & $(24.13 \mathrm{~cm})$ & $6.127 \times 10^{-4}$ & \\
\hline 9.75 & $(24.77 \mathrm{~cm})$ & $5.816 \times 10^{-4}$ & \\
\hline 10.00 & $(25.40 \mathrm{~cm})$ & $5.527 \times 10^{-4}$ & $5.563 \times 10^{-4}$ \\
\hline 10.25 & $(26.04 \mathrm{~cm})$ & $5.258 \times 10^{-4}$ & \\
\hline 10.50 & $(26.67 \mathrm{~cm})$ & $5.009 \times 10^{-4}$ & \\
\hline 10.75 & $(27.31 \mathrm{~cm})$ & $4.776 \times 10^{-4}$ & \\
\hline 11.00 & $(27.94 \mathrm{~cm})$ & $4.559 \times 10^{-4}$ & \\
\hline 11.25 & $(28.58 \mathrm{~cm})$ & $4.357 \times 10^{-4}$ & \\
\hline 11.50 & ( $29.21 \mathrm{~cm})$ & $4.167 \times 10^{-4}$ & \\
\hline 11.75 & $(29.85 \mathrm{~cm})$ & $3.989 \times 10^{-4}$ & \\
\hline 12.00 & $(30.48 \mathrm{~cm})$ & $3.822 \times 10^{-4}$ & \\
\hline 12.25 & $(31.12 \mathrm{~cm})$ & $3.666 \times 10^{-4}$ & \\
\hline 12.50 & $(31.75 \mathrm{~cm})$ & $3.518 \times 10^{-4}$ & \\
\hline 12.75 & $(32.39 \mathrm{~cm})$ & $3.379 \times 10^{-4}$ & \\
\hline 13.00 & $(33.02 \mathrm{~cm})$ & $3.248 \times 10^{-4}$ & \\
\hline 13.25 & $(33.66 \mathrm{~cm})$ & $3.125 \times 10^{-4}$ & \\
\hline 13.50 & $(34.29 \mathrm{~cm})$ & $3.008 \times 10^{-4}$ & \\
\hline 13.75 & $(34.93 \mathrm{~cm})$ & $2.897 \times 10^{-4}$ & \\
\hline 14.00 & $(35.56 \mathrm{~cm})$ & $2.793 \times 10^{-4}$ & $2.810 \times 10^{-4}$ \\
\hline
\end{tabular}

Table 3. Numerical listing of the calculated and measured efficiencies for the $8 \times 5$ in source

\begin{tabular}{|c|c|c|c|}
\hline \multicolumn{2}{|c|}{$\begin{array}{l}\text { Source to detector } \\
\text { distance in in }\end{array}$} & \multirow{2}{*}{$\begin{array}{l}\begin{array}{c}\text { Calculated } \\
\text { efficiency }\end{array} \\
3.094 \times 10^{-3}\end{array}$} & \multirow{2}{*}{$\begin{array}{c}\begin{array}{c}\text { Measured } \\
\text { efficiency }\end{array} \\
3.904 \times 10^{-3}\end{array}$} \\
\hline 3.00 & $(7.62 \mathrm{~cm})$ & & \\
\hline 3.25 & $(8.26 \mathrm{~cm})$ & $2.827 \times 10^{-3}$ & \\
\hline 3.50 & $(8.89 \mathrm{~cm})$ & $2.611 \times 10^{-3}$ & \\
\hline 3.75 & $(9.53 \mathrm{~cm})$ & $2.421 \times 10^{-3}$ & \\
\hline 4.00 & $(10.16 \mathrm{~cm})$ & $2.247 \times 10^{-3}$ & $2.250 \times 10^{-3}$ \\
\hline 4.25 & $(10.80 \mathrm{~cm})$ & $2.088 \times 10^{-3}$ & \\
\hline 4.50 & $(11.43 \mathrm{~cm})$ & $1.940 \times 10^{-3}$ & \\
\hline 4.75 & $(12.07 \mathrm{~cm})$ & $1.804 \times 10^{-3}$ & \\
\hline 5.00 & $(12.70 \mathrm{~cm})$ & $1.679 \times 10^{-3}$ & \\
\hline 5.25 & $(13.34 \mathrm{~cm})$ & $1.564 \times 10^{-3}$ & \\
\hline 5.50 & $(13.97 \mathrm{~cm})$ & $1.458 \times 10^{-3}$ & \\
\hline 5.75 & $(14.61 \mathrm{~cm})$ & $1.361 \times 10^{-3}$ & \\
\hline 6.00 & $(15.24 \mathrm{~cm})$ & $1.273 \times 10^{-3}$ & \\
\hline 6.25 & $(15.88 \mathrm{~cm})$ & $1.191 \times 10^{-3}$ & \\
\hline 6.50 & $(16.51 \mathrm{~cm})$ & $1.117 \times 10^{-3}$ & \\
\hline 6.75 & $(17.15 \mathrm{~cm})$ & $1.048 \times 10^{-3}$ & \\
\hline 7.00 & $(17.78 \mathrm{~cm})$ & $9.854 \times 10^{-4}$ & $9.800 \times 10^{-4}$ \\
\hline 7.25 & $(18.42 \mathrm{~cm})$ & $9.276 \times 10^{-4}$ & \\
\hline 7.50 & $(19.05 \mathrm{~cm})$ & $8.743 \times 10^{-4}$ & \\
\hline 7.75 & $(19.69 \mathrm{~cm})$ & $8.252 \times 10^{-4}$ & \\
\hline 8.00 & $(20.32 \mathrm{~cm})$ & $7.798 \times 10^{-4}$ & \\
\hline 8.25 & ( $20.96 \mathrm{~cm})$ & $7.379 \times 10^{-4}$ & \\
\hline 8.50 & $(21.59 \mathrm{~cm})$ & $6.990 \times 10^{-4}$ & \\
\hline 8.75 & $(22.23 \mathrm{~cm})$ & $6.630 \times 10^{-4}$ & \\
\hline 9.00 & $(22.86 \mathrm{~cm})$ & $6.296 \times 10^{-4}$ & \\
\hline 9.25 & $(23.50 \mathrm{~cm})$ & $5.985 \times 10^{-4}$ & \\
\hline 9.50 & $(24.13 \mathrm{~cm})$ & $5.695 \times 10^{-4}$ & \\
\hline 9.75 & $(24.77 \mathrm{~cm})$ & $5.425 \times 10^{-4}$ & \\
\hline 10.00 & $(25.40 \mathrm{~cm})$ & $5.173 \times 10^{-4}$ & $5.188 \times 10^{-4}$ \\
\hline 10.25 & $(26.04 \mathrm{~cm})$ & $4.938 \times 10^{-4}$ & \\
\hline 10.50 & ( $26.67 \mathrm{~cm})$ & $4.717 \times 10^{-4}$ & \\
\hline 10.75 & $(27.31 \mathrm{~cm})$ & $4.511 \times 10^{-4}$ & \\
\hline 11.00 & $(27.94 \mathrm{~cm})$ & $4.317 \times 10^{-4}$ & \\
\hline 11.25 & $(28.58 \mathrm{~cm})$ & $4.135 \times 10^{-4}$ & \\
\hline 11.50 & $(29.21 \mathrm{~cm})$ & $3.964 \times 10^{-4}$ & \\
\hline 11.75 & $(29.85 \mathrm{~cm})$ & $3.803 \times 10^{-4}$ & \\
\hline 12.00 & $(30.48 \mathrm{~cm})$ & $3.651 \times 10^{-4}$ & \\
\hline 12.25 & $(31.12 \mathrm{~cm})$ & $3.508 \times 10^{-4}$ & \\
\hline 12.50 & $(31.75 \mathrm{~cm})$ & $3.372 \times 10^{-4}$ & \\
\hline 12.75 & $(32.39 \mathrm{~cm})$ & $3.245 \times 10^{-4}$ & \\
\hline 13.00 & $(33.02 \mathrm{~cm})$ & $3.124 \times 10^{-4}$ & \\
\hline 13.25 & $(33.66 \mathrm{~cm})$ & $3.009 \times 10^{-4}$ & \\
\hline 13.50 & $(34.29 \mathrm{~cm})$ & $2.901 \times 10^{-4}$ & \\
\hline 13.75 & $(34.93 \mathrm{~cm})$ & $2.798 \times 10^{-4}$ & \\
\hline 14.00 & $(35.56 \mathrm{~cm})$ & $2.700 \times 10^{-4}$ & $2.733 \times 10^{-4}$ \\
\hline
\end{tabular}




\section{Acknowledgment}

The authors are grateful to S. J. Bright for performing many of the early measurements which provided a basis for organizing the final sets of measurements, and to F. J. Schima for the data in Figs. 5 and 7. This work was partially supported by grants from the United States Air Force, Newark Air Force Base, Newark, OH (U.S. Air Force Contract No. 2803 ABG/ACFS) and the Department of the Navy, NAV/Sea Systems Command, Alexandria, VA.

\section{References}

[1] C. C. Grosjean and W. Bossaert, Table of Absolute Detection Efficiencies of Cylindrical Scintillation Gamma-Ray Detectors, Computing Laboratory of the University of Ghent, Jozef Plateaustraat 22, Ghent, Belgium (1965).

[2] Nuclear Weapon Accident Response Procedures (NARP) Manual, developed by the Defense Nuclear Agency, Washington, D.C. 20305 (January 24, 1984).

[3] J. M. R. Hutchinson and S. J. Bright, The NBS Large Area Alpha-Particle Counting Systems, J. Res. Natl. Bur. Stand. 92, 311 (1987).

[4] L. L. Lucas and J. M. R. Hutchinson, Study of the Scattering Correction for Thick Uranium-Oxide and Other AlphaParticle Sources (Part 1: Theoretical), Int. J. Appl. Rad. Isotopes 27, 35 (1976).

About the authors: J. M. R. Hutchinson, M. $P$. Unterweger, and P. A. Hodge are members of the Radioactivity Group of the Ionizing Radiation Division at NIST's Physics Laboratory. 